\title{
Fluorinated azobenzenes as supramolecular halogen-bonding building blocks
}

\author{
Esther Nieland ${ }^{1}$, Oliver Weingart ${ }^{* 2}$ and Bernd M. Schmidt ${ }^{* 1}$
}

\section{Letter}

\section{Address:}

${ }^{1}$ Institut für Organische Chemie und Makromolekulare Chemie, Heinrich-Heine-Universität Düsseldorf, Universitätsstraße 1, D-40225 Düsseldorf, Germany and ${ }^{2}$ Institut für Theoretische Chemie und Computerchemie, Heinrich-Heine-Universität Düsseldorf, Universitätsstraße 1, D-40225 Düsseldorf, Germany

\section{Email:}

Oliver Weingart ${ }^{*}$ - Oliver.Weingart@hhu.de; Bernd M. Schmidt ${ }^{*}$ Bernd.Schmidt@hhu.de

* Corresponding author

Keywords:

azobenzene; DFT calculations; fluorine chemistry; halogen bonding; photochemistry

\author{
Beilstein J. Org. Chem. 2019, 15, 2013-2019. \\ doi:10.3762/bjoc. 15.197 \\ Received: 01 July 2019 \\ Accepted: 16 August 2019 \\ Published: 23 August 2019 \\ This article is part of the thematic issue "Molecular switches". \\ Guest Editor: W. Szymanski \\ (C) 2019 Nieland et al.; licensee Beilstein-Institut. \\ License and terms: see end of document.
}

\begin{abstract}
ortho-Fluoroazobenzenes are a remarkable example of bistable photoswitches, addressable by visible light. Symmetrical, highly fluorinated azobenzenes bearing an iodine substituent in para-position were shown to be suitable supramolecular building blocks both in solution and in the solid state in combination with neutral halogen bonding acceptors, such as lutidines. Therefore, we investigate the photochemistry of a series of azobenzene photoswitches. Upon introduction of iodoethynyl groups, the halogen bonding donor properties are significantly strengthened in solution. However, the bathochromic shift of the $\pi \rightarrow \pi^{*}$ band leads to a partial overlap with the $n \rightarrow \pi^{*}$ band, making it slightly more difficult to address. The introduction of iodine substituents is furthermore accompanied with a diminishing thermal half-life. A series of three azobenzenes with different halogen bonding donor properties are discussed in relation to their changing photophysical properties, rationalized by DFT calculations.
\end{abstract}

\section{Introduction}

The halogen bond is an attractive noncovalent interaction between a polarized halogen atom (the halogen bond donor) and a Lewis base (the halogen bond acceptor) [1,2]. A prominent example regarding the origin of halogen bonding can be found in inorganic solid-state chemistry. The structurally diverse group of polyiodides, with its rich structural chemistry is governed by halogen bonding, where $\mathrm{I}^{-}$and $\mathrm{I}_{3}^{-}$are considered the nucleo- philic (halogen bond acceptor) and $\mathrm{I}_{2}$ the electrophilic (halogen bond donor) subcomponent [3-7]. Neutral halogen bonds on the other hand can be generally described by $\mathrm{R}-\mathrm{X} \cdots \mathrm{Y}$, where $\mathrm{R}-\mathrm{X}$ is the halogen bond donor, $\mathrm{R}$ is covalently bound to $\mathrm{X}$, and $\mathrm{Y}$ is the Lewis basic halogen bond acceptor [1]. In recent years, halogen bonding was used to assemble molecules, leading to a variety of supramolecular architectures [8-19], as well as 
discrete supermolecules [20-24]. Huber and co-workers demonstrated the activation of a carbonyl group by halogen bonding, and successfully applied this concept to catalysts for Michael addition reactions [25] and also employed neutral [26], and hypervalent iodolium derivatives as activators in a halide abstraction reaction and as organocatalysts in Diels-Alder reactions [27]. The group of Metrangolo also reported halogen bonding-promoted catalysis in water by exploiting a halogen bonding amino acid, which combines excellent donor properties with good water solubility [28], in addition to their seminal contributions in the field of crystal engineering [1]. Only few supramolecular capsules were reported so far [29], including the resorcin[4]arene capsules of Diederich and co-workers [21,23], triangular macrocycles assembled by self-complemented halogen bonding [20] and halogen bond templated, polyfluorinated stilbene squares used for topochemical polymerization [22]. Additionally, halonium ions $\left[\mathrm{N} \cdots \mathrm{I}^{+} \cdots \mathrm{N}\right]$ were reported to form several charged, discrete supramolecular capsules [30-33] and helicates [34]. In the same line, we have demonstrated recently that both $E-4,4^{\prime}$-di(iodo)perfluoroazobenzene (A2) and E-4,4'-di(iodoethynyl)perfluoroazobenzene (A3) halogen bond donors can be combined with rigid u-shaped anthracene building blocks, bearing two 3,5-lutidine acceptors in 1 and 8 positions, to form self-assembled boxes of 25-30 Å length in solution and in the solid state [35].

We chose azobenzene because azobenzene is one of the simplest molecules that can undergo photoinduced isomerisation of its $\mathrm{N}=\mathrm{N}$ central double bond. The photoisomerisation reaction in $n \rightarrow \pi$ and $\pi \rightarrow \pi^{*}$ excited states has been studied with experimental [36-38] and theoretical approaches [39-44]. By substituting azobenzenes in the ortho-positions to the $\mathrm{N}=\mathrm{N}$ bond with electron-withdrawing fluorine substituents $[45,46]$, the red-shifting of the $n \rightarrow \pi^{*}$ transitions enables selective addressing of both the $E$ - and $Z$-isomer using visible light. Stabilization of the n-orbitals in the $Z$-isomers leads to a very high thermal stability of the $Z$-isomer, now exhibiting thermal half-lives up to two years at room temperature [36]. Most important for application in supramolecular systems, it should be possible to study both states of the system on a laboratory timescale, a key aspect in the design of our halogen bonded boxes [35]. Therefore, we herein present a comprehensive investigation of the photochemistry of highly fluorinated azobenzenes. Our efforts are supported by theoretical calculations, showing that these azobenzenes are suitable for the use as building blocks in supramolecular architectures.

\section{Results and Discussion}

Three different azobenzenes A1-3 were studied with regard to halogen bonding and photochemical properties (Scheme 1).

In our experiments, tetrafluorinated $\mathbf{A} \mathbf{1}$ does not form halogen bonded boxes with acceptor $\mathbf{U 1}$, neither in solution, nor in the solid state. Octafluorinated A2 forms [2 + 2] boxes in the solid state and possibly in solution, whereas tetrafluoroiodoethynyl A3 is as donor strong enough to reliably permit the characterization of the boxes formed in solution and in the solid state [35]. Electrostatic interaction plays a dominant role in halogen bonding $[1,12,13]$. Therefore, we calculated the molecular electrostatic potentials of the halogen bond donors A1-3 to visualize their capabilities to form halogen bonded architectures (Figure 1).

Looking at the electrostatic surface potentials of the halogen bond donors, one can see that $\mathbf{A 3}$ shows a maximum value on the iodine atom that is most positive compared to that of $\mathbf{A 2}$ and A1. The evolution of the iodine potential follows our experimental observation with iodoethynylazobenzene $\mathbf{A 3}$ being the strongest halogen bond donor and $\mathbf{A 1}$ being the weakest, within this series [48]. For potential, reversible photochemical control of supramolecular assemblies, the halogen donors need to bind both in the $E$ - and $Z$-state. This is the case according to our a)<smiles>[R]c1c([R])c(F)c(N=Nc2c(F)c([R])c([R])c(F)c2F)c(F)c1[R]</smiles>

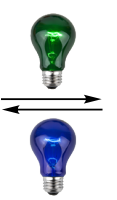

A1 $R^{1}=H, R^{2}=1$

A2 $R^{1}=F, R^{2}=$ I

A3 $\mathrm{R}^{1}=\mathrm{F}, \mathrm{R}^{2}=\xi \equiv \mathrm{I}$ b)<smiles>[R]c1c([R])c([R])c(N=Nc2c(F)c([R])c([R])c(F)c2F)c(F)c1[R]</smiles>

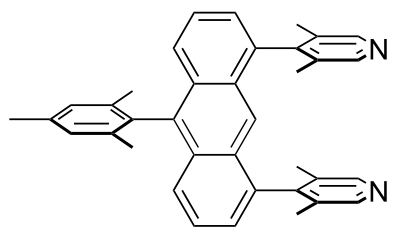

U1

Scheme 1: a) Azobenzenes A1-3 employed in this study. b) U-shaped anthracene halogen bond acceptor bearing two 3,5-lutidines in 1 and 8 positions. 
a)
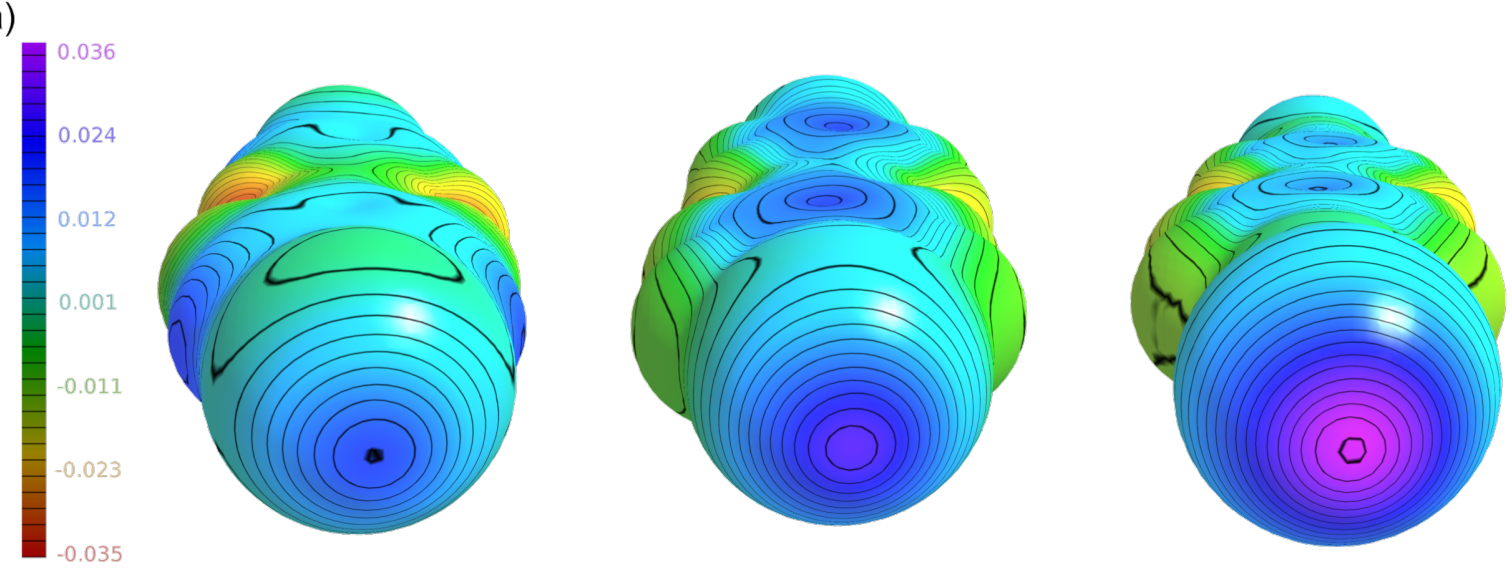

A1

A2

A3
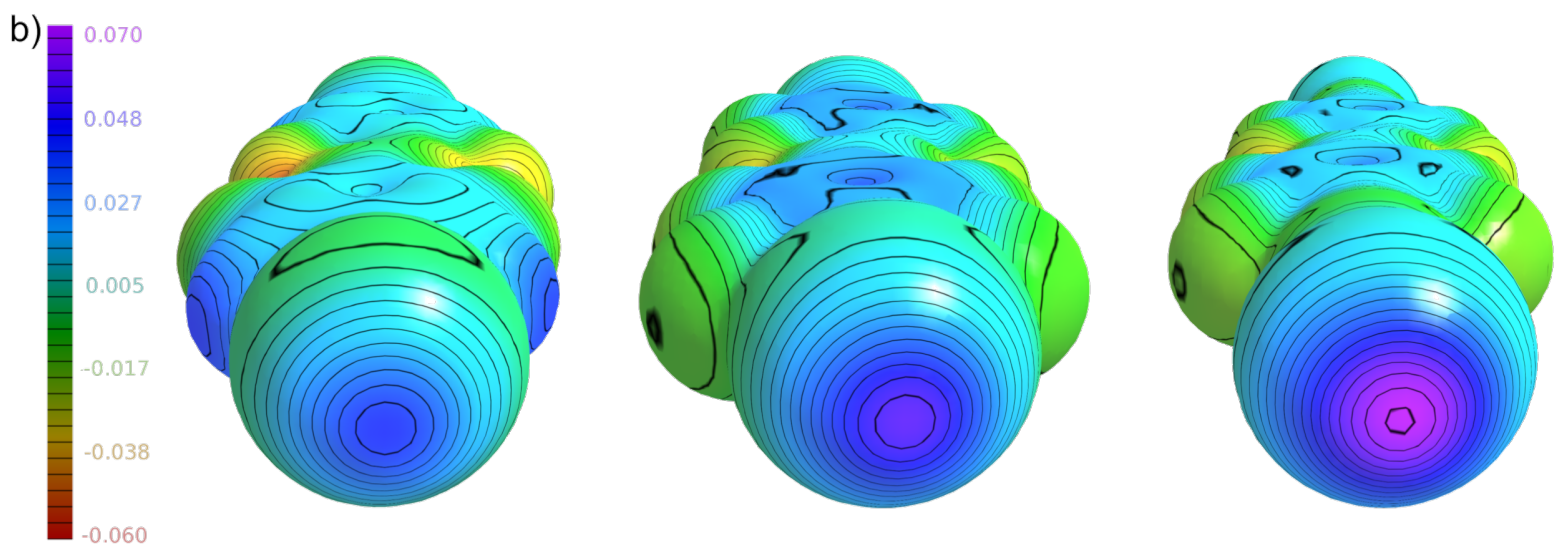

Figure 1: Electrostatic potential map at different isodensity values (B3LYP/ def2/TZVP/DGZVP optimized geometries) with a) $\rho=0.0001$, and b) $\rho=0.001$. For visualization, the MoleCoolQt software was used [47].

computations, as isodensity values remain almost identical upon switching (Figure S14 in Supporting Information File 1). We therefore turned our attention to elucidate the change of photochemical properties upon introducing the heavy iodine to the azobenzene building block, as well as the effect of the ethynyl group in case of $\mathbf{A 3}$ (Figure 2). Vertical electronic absorption spectra of the different azobenzenes were calculated at the TD-B3LYP/def2-TZVP level of theory including Grimme D3 dispersion correction, using the Gaussian 16 program package (see Supporting Information File 1). The azobenzenes were embedded in a continuum using the polarizable continuum model (PCM) for the solvent MeCN. The DGZVP all electron basis was used for iodine. Vertical excitation energies for the $\pi \rightarrow \pi^{*}$ and $n \rightarrow \pi^{*}$ transitions of $E$ and $Z$-isomers are listed in the Table S9 (Supporting Information File 1).

The computational absorption spectra are in fair agreement with the experimental ones (Table 1) and trends are reproduced accordingly (measured and calculated absorption spectra of A1 can be found in the Supporting Information File 1, Figures S1 and S12). By introduction of fluorine atoms ortho to the azo bond, the two $n \rightarrow \pi^{*}$ of $E$ - and $Z$-state become sufficiently separated to address them individually using visible light sources. Along with averting UV light for the photochemical reaction, high PSS ratios can be observed, which is very desirable for application in supramolecular systems $[12,13,35]$. Tetra- and octafluorinated A1 and A2 show clear spectral separation of the $\mathrm{n} \rightarrow \pi^{*}$ bands, whereas the extended $\pi$-system of iodoethynyl $\mathbf{A 3}$ lead to a bathochromic shift of the $\pi \rightarrow \pi^{*}$ band by $24 \mathrm{~nm}$, now partially overlapping with the, also broadened, $n \rightarrow \pi^{*}$ band of $Z$-A3. Apart from the photoisomerisation using light, azobenzenes A1-3 also undergo thermal back reaction, which we studied experimentally and theoretically. To gain insight into the effect of the iodine atoms on the thermal stability we investigated A1, A2 and $\mathbf{A 3}$ in $\mathrm{MeCN}$ at elevated temperature $\left(60{ }^{\circ} \mathrm{C}\right)$, following the works of Hecht and co-workers $[45,46]$. The data is presented in Table 2. Additionally, we studied $\mathbf{A 3}$ in a wide range of temperatures in $\mathrm{MeCN}$. 
a)

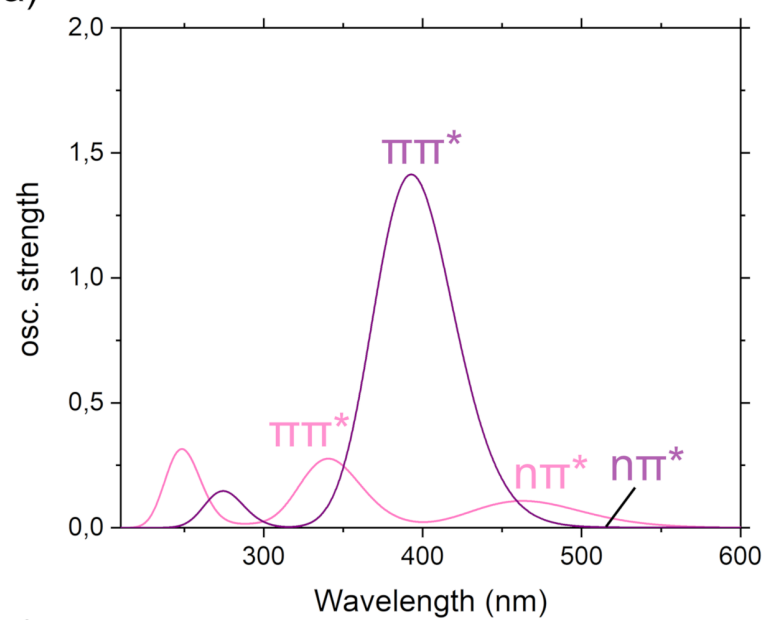

c)

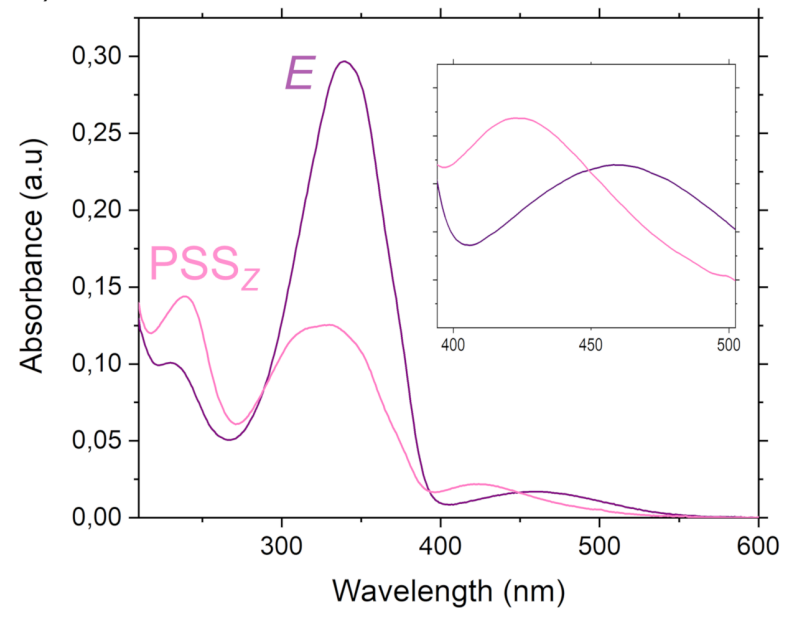

b)

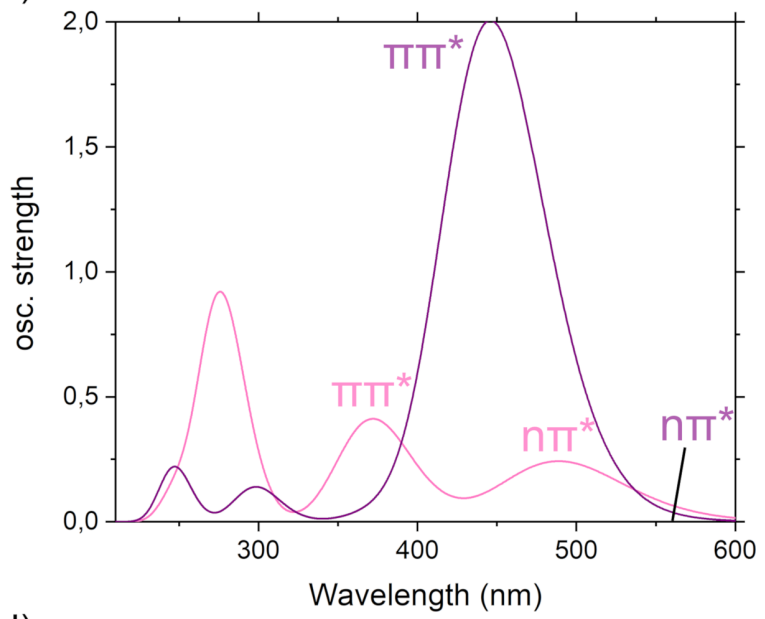

d)

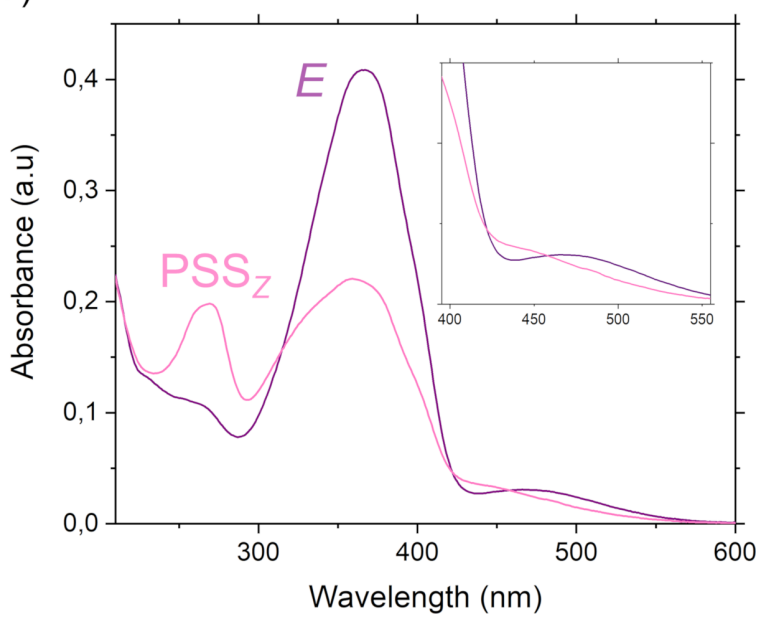

Figure 2: Top: Vertical electronic absorption spectra of a) A2 and b) A3, calculated using TD-B3LYP/def2-TZVP level of theory with Grimme D3 dispersion corrections and implicit MeCN solvent. Pink line: $Z$-isomer, purple line: $E$-isomer. Bottom: $E$-state of $\mathrm{c}$ ) $\mathbf{A} 2$ and d) $\mathbf{A} 3$ (from left to right, purple) and photostationary state (PSS, pink) after photoirradiation with $\lambda_{\text {irr }}=565 \mathrm{~nm}$, monitored by UV-vis (MeCN, $c=10.5$ and $9.3 \mu$ mol/L, respectively). The inlets of c) and d) were smoothed using the Savitzky-Golay filter implemented in OriginPro to facilitate readability.

Table 1: Spectroscopic properties in MeCN for E-state and PSS after photoirradiation with $\lambda_{\text {irr }}=565 \mathrm{~nm}$. Maxima were determined using the "Peak Analyzer" implemented in OriginPro. Kinetic measurements were performed in $\mathrm{MeCN}$ at $60^{\circ} \mathrm{C}$ (Supporting Information File 1).

\begin{tabular}{lcccc} 
& $\begin{array}{c}\lambda_{\max }(E) \\
{[\mathrm{nm}]}\end{array}$ & $\begin{array}{c}\varepsilon_{\max }(E) \\
{\left[\mathrm{M}^{-1} \mathrm{~cm}^{-1}\right]}\end{array}$ & $\begin{array}{c}\lambda_{\text {max }}\left(P S S_{Z}\right) \\
{[\mathrm{nm}]}\end{array}$ & $\begin{array}{c}\varepsilon_{\text {max }}\left(P S S_{Z}\right) \\
{\left[\mathrm{M}^{-1} \mathrm{~cm}^{-1}\right]}\end{array}$ \\
\hline A1 & 335 & $3.48 \times 10^{4}$ & 241 & $1.68 \times 10^{4}$ \\
A2 & 340 & $2.84 \times 10^{4}$ & 239 & $1.38 \times 10^{4}$ \\
{$[\mathrm{~h}]$} & 359 & $2.38 \times 10^{4}$
\end{tabular}

The half-lives decrease from $\mathbf{A 1}$ to $\mathbf{A 3}$, an effect that correlates with the increase in dipole moment of the transition state (TS, see Supporting Information File 1, Table S8). In the B3LYP computations this value is larger than for the corresponding $Z$-isomer and leads to a stabilization of the TS in polar solvents [46].
The bistable character is obviously weakened upon improving the halogen bonding properties. However, most importantly, the azobenzenes still can be conveniently handled at room temperature with a half-life of at least a working day, allowing for studying both states of the systems without needs for in situ irradiation (the thermal half-life of $\mathbf{A 3}$ at room temperature is 
Table 2: Activation process parameters for the $E \rightarrow Z$ isomerisation in MeCN at $60^{\circ} \mathrm{C}, \mathrm{B} 3 \mathrm{LYP}$, def-TZVP basis for $\mathrm{C}, \mathrm{H}, \mathrm{N}, \mathrm{F}, \mathrm{DGZVP}$ all electron basis for iodine. Grimme D3 dispersion correction was applied. Values were computed using the KistHelp program [49] employing classical transition state theory and including the effects of Wigner-tunnelling (Supporting Information File 1).

\begin{tabular}{cccccccc} 
& $\begin{array}{c}\Delta U \\
{\left[\mathrm{~kJ} \mathrm{~mol}^{-1}\right]}\end{array}$ & $\begin{array}{c}\Delta G \\
{\left[\mathrm{KJ} \mathrm{mol}^{-1}\right]}\end{array}$ & $\begin{array}{c}\Delta H \\
{\left[\mathrm{~kJ} \mathrm{~mol}^{-1}\right]}\end{array}$ & $\begin{array}{c}\Delta S \\
\left.[\mathrm{~J} \mathrm{~mol})^{-1}\right]\end{array}$ & $\begin{array}{c}k \mathrm{~K}-E \\
{\left[\mathrm{~s}^{-1}\right]}\end{array}$ & $\begin{array}{c}\mathrm{T}_{1 / 2} \\
{[\mathrm{~h}]}\end{array}$ & $\begin{array}{c}\mathrm{T}_{1 / 2} \exp . \\
{[\mathrm{h}]}\end{array}$ \\
\hline A1 & 124.10 & 114.32 & 119.06 & 14.22 & $9.46 \times 10^{-6}$ & 20.35 & 44.92 \\
A2 & 118.86 & 108.73 & 114.49 & 17.28 & $7.06 \times 10^{-6}$ & 2.73 & 17.17 \\
A3 & 113.13 & 99.89 & 108.69 & 26.42 & $1.70 \times 10^{-6}$ & 0.11 & 0.92
\end{tabular}

14.98 hours in MeCN, see the Supporting Information File 1, Figures S6-S8).

In addition to that, slow evaporation of an equimolar solution of $\mathbf{U 1}$ and $\mathbf{A 2}$ in benzene furnished red-orange single crystals suitable for X-ray analysis of a $[2+2]$ halogen-bonded box, U1 $\cdots \mathbf{A 2}$, over the course of a few days in quantitative yield. Single-crystal analysis confirms the formation of a $\mathbf{U 1} \cdots \mathbf{A 2}$ box in the solid state (Figure 3).

The $\mathbf{U 1} \cdots \mathbf{A} 2$ box has a principal length of approximately $25 \AA$ (anthracene-anthrance distance) and a height of $5 \AA$ (distance between the ipso-carbons of the lutidines). The lutidine acceptor units are curved inwards (with N...I-C angles of 165 and $172^{\circ}$ ) and show N $\cdots$ I distances of 2.78 and $2.82 \AA$ to the azobenzene donors. As observed for the other boxes assembled by halogen bonding reported by us [35], parts containing fluorinated azobenzenes $\mathbf{A 2}$ are segregated from the perhydrogenated anthracene $\mathbf{U} \mathbf{1}$ units, connected by $\mathrm{C}-\mathrm{H} \cdots \mathrm{F}$ contacts. The azobenzenes $\mathbf{A 2}$ interact by lamellar 2D $\pi$-stacking, anthracene U1 interact predominantly by $\mathrm{C}-\mathrm{H} \cdots \pi$ interactions as both the solubilizing mesitylene group and the two perpendicular lutidine acceptors effectively prevent stacking of the anthracenes body (Supporting Information File 1, Figure S17). This was also the key to being able to lower the temperature to characterize formation in the ${ }^{1} \mathrm{H}$ NMR, where the solubility of the assemblies in benzene was improved by adding a solubilizing mesitylene group to the halogen bonding acceptor $\mathbf{U} \mathbf{1}$ to avoid precipitation of box A2 $\cdots \mathbf{U} \mathbf{1}$ during previous titration experiments [35].

\section{Conclusion}

The performed calculations show that both $E$ - and $Z$-isomer are equally able to undergo halogen bonding. By improving the strength of halogen bonding going from tetrafluorinated A1 to octafluorinated $\mathbf{A 2}$ to $\mathbf{A 3}$, especially by introducing the

\section{a)}

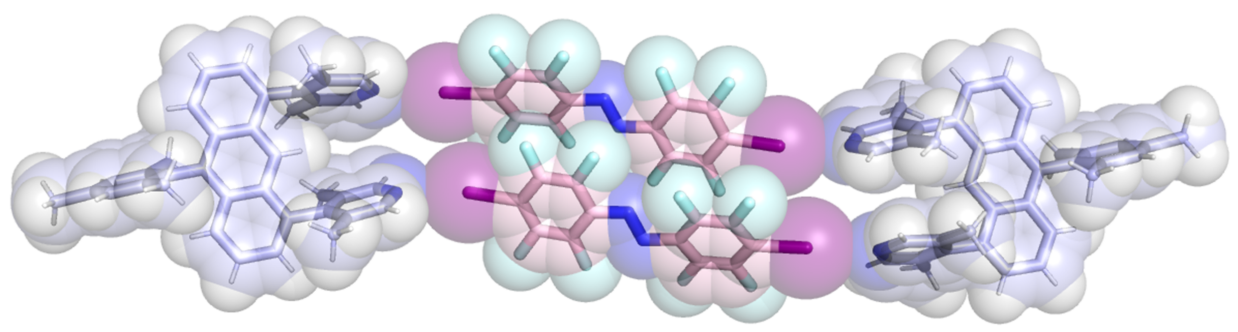

b)

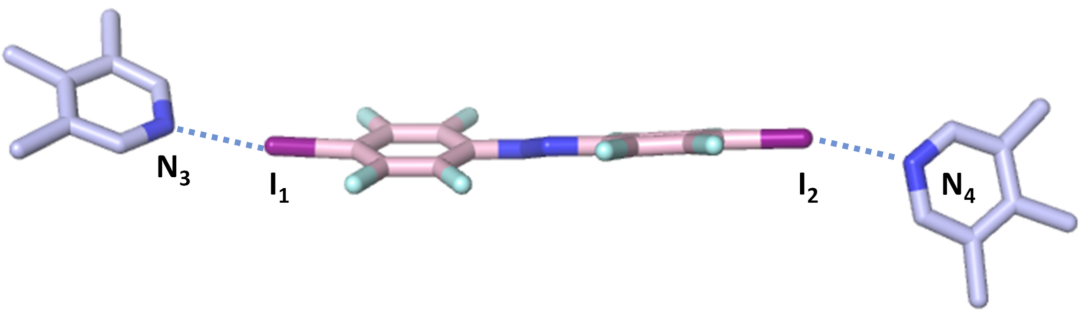

Figure 3: a) Space-filling model of U1 $\cdots \mathbf{A} 2$. The kinked alignment of both the lutidine units of U1 and the azobenzenes A2 can be seen. b) Part of the $X$-ray crystal structure showing the halogen bonding azobenzene A2 in detail. Selected bond lengths: $\mathrm{N}_{3}-\mathrm{I}_{1} 2.7810(2), \mathrm{I}_{2}-\mathrm{N}_{4} 2.816(2) \AA$. 
iodoethynyl group, as trade-off, photophysical properties are changing. The bathochromic shift of the $\pi \rightarrow \pi^{*}$ band leads to an overlap with the $n \rightarrow \pi^{*}$ excitation, making it more difficult to address, together with a diminishing thermal half-life. Both effects can be qualitatively reproduced and understood with the help of quantum mechanical calculations involving a combination of low-cost implicit solvation models and hybrid density functionals when including dispersion corrections.

\section{Supporting Information}

\section{Supporting Information File 1}

General experimental information, synthetic procedures,

UV-vis photochemistry and kinetic studies, computational methods, and X-ray crystallographic details.

[https://www.beilstein-journals.org/bjoc/content/ supplementary/1860-5397-15-197-S1.pdf]

\section{Acknowledgements}

We acknowledge the Fonds der Chemischen Industrie for a material cost allowance grant (B.M.S) and the Strategic Research Fund of Heinrich Heine University (F-2018/1460-4). E.N. is supported by a Deutschlandstipendium. We thank Y. Garmshausen for his advices on azobenzene photochemistry and C. Czekelius for sharing analytical equipment. Computational support and infrastructure was provided by the "Centre for Information and Media Technology" (ZIM) at the Heinrich Heine University.

\section{ORCID ${ }^{\circledR}$ iDs}

Esther Nieland - https://orcid.org/0000-0001-5213-6303 Oliver Weingart - https://orcid.org/0000-0001-6033-3702 Bernd M. Schmidt - https://orcid.org/0000-0003-3622-8106

\section{References}

1. Cavallo, G.; Metrangolo, P.; Milani, R.; Pilati, T.; Priimagi, A.; Resnati, G.; Terraneo, G. Chem. Rev. 2016, 116, 2478-2601. doi:10.1021/acs.chemrev.5b00484

2. Gilday, L. C.; Robinson, S. W.; Barendt, T. A.; Langton, M. J.; Mullaney, B. R.; Beer, P. D. Chem. Rev. 2015, 115, 7118-7195. doi:10.1021/cr500674c

3. Peuronen, A.; Rinta, H.; Lahtinen, M. CrystEngComm 2015, 17 , 1736-1740. doi:10.1039/c4ce01866d

4. Reiss, G. J. Z. Kristallogr. - New Cryst. Struct. 2019, 234, 737-739. doi:10.1515/ncrs-2019-0082

5. van Megen, M.; Reiss, G. J. Inorganics 2013, 1, 3-13. doi:10.3390/inorganics1010003

6. Reiss, G. J.; van Megen, M. Z. Naturforsch., B: J. Chem. Sci. 2012, 67, 5-10. doi:10.5560/znb.2012.67b0005

7. Svensson, P. H.; Kloo, L. Chem. Rev. 2003, 103, 1649-1684. doi:10.1021/cr0204101
8. Aakeröy, C. B.; Baldrighi, M.; Desper, J.; Metrangolo, P.; Resnati, G. Chem. - Eur. J. 2013, 19, 16240-16247. doi:10.1002/chem.201302162

9. Resnati, G.; Boldyreva, E.; Bombicz, P.; Kawano, M. IUCrJ 2015, 2, 675-690. doi:10.1107/s2052252515014608

10. Dichiarante, V.; Kaiho, T.; Metrangolo, P.; Pilati, T.; Resnati, G.; Terraneo, G.; Ursini, M. Chem. Commun. 2019, 55, 4234-4237. doi:10.1039/c9cc01092k

11. Szell, P. M. J.; Zablotny, S.; Bryce, D. L. Nat. Commun. 2019, 10, 916. doi:10.1038/s41467-019-08878-8

12. Saccone, M.; Spengler, M.; Pfletscher, M.; Kuntze, K.; Virkki, M.; Wölper, C.; Gehrke, R.; Jansen, G.; Metrangolo, P.; Priimagi, A.; Giese, M. Chem. Mater. 2019, 31, 462-470. doi:10.1021/acs.chemmater.8b04197

13. Saccone, M.; Kuntze, K.; Ahmed, Z.; Siiskonen, A.; Giese, M.; Priimagi, A. J. Mater. Chem. C 2018, 6, 9958-9963. doi:10.1039/c8tc02611d

14. Han, C.; Zhao, D.; Dong, S. Chem. Commun. 2018, 54, 13099-13102. doi:10.1039/c8cc07993e

15. Nikolayenko, V. I.; Castell, D. C.; van Heerden, D. P.; Barbour, L. J. Angew. Chem., Int. Ed. 2018, 57, 12086-12091. doi:10.1002/anie.201806399

16. Pfrunder, M. C.; Brock, A. J.; Brown, J. J.; Grosjean, A.; Ward, J.; McMurtrie, J. C.; Clegg, J. K. Chem. Commun. 2018, 54, 3974-3976. doi:10.1039/c8cc02178c

17. Liu, P.; Li, Z.; Shi, B.; Liu, J.; Zhu, H.; Huang, F. Chem. - Eur. J. 2018, 24, 4264-4267. doi:10.1002/chem.201800312

18. Bai, L.; Bose, P.; Gao, Q.; Li, Y.; Ganguly, R.; Zhao, Y. J. Am. Chem. Soc. 2017, 139, 436-441. doi:10.1021/jacs.6b11057

19. Priimagi, A.; Cavallo, G.; Forni, A.; Gorynsztejn-Leben, M.; Kaivola, M.; Metrangolo, P.; Milani, R.; Shishido, A.; Pilati, T.; Resnati, G.; Terraneo, G. Adv. Funct. Mater. 2012, 22, 2572-2579. doi:10.1002/adfm.201200135

20. Szell, P. M. J.; Siiskonen, A.; Catalano, L.; Cavallo, G.; Terraneo, G.; Priimagi, A.; Bryce, D. L.; Metrangolo, P. New J. Chem. 2018, 42, 10467-10471. doi:10.1039/c8nj00759d

21. Dumele, O.; Schreib, B.; Warzok, U.; Trapp, N.; Schalley, C. A.; Diederich, F. Angew. Chem., Int. Ed. 2017, 56, 1152-1157. doi:10.1002/anie.201610884

22. Sinnwell, M. A.; MacGillivray, L. R. Angew. Chem., Int. Ed. 2016, 55, 3477-3480. doi:10.1002/anie.201510912

23. Dumele, O.; Trapp, N.; Diederich, F. Angew. Chem., Int. Ed. 2015, 54, 12339-12344. doi:10.1002/anie.201502960

24. Jungbauer, S. H.; Bulfield, D.; Kniep, F.; Lehmann, C. W.; Herdtweck, E.; Huber, S. M. J. Am. Chem. Soc. 2014, 136, 16740-16743. doi:10.1021/ja509705f

25. Gliese, J.-P.; Jungbauer, S. H.; Huber, S. M. Chem. Commun. 2017, 53, 12052-12055. doi:10.1039/c7cc07175b

26. Walter, S. M.; Jungbauer, S. H.; Kniep, F.; Schindler, S.; Herdtweck, E.; Huber, S. M. J. Fluorine Chem. 2013, 150, 14-20. doi:10.1016/j.jluchem.2013.02.027

27. Heinen, F.; Engelage, E.; Dreger, A.; Weiss, R.; Huber, S. M. Angew. Chem., Int. Ed. 2018, 57, 3830-3833. doi:10.1002/anie.201713012

28. Bergamaschi, G.; Lascialfari, L.; Pizzi, A.; Martinez Espinoza, M. I.; Demitri, N.; Milani, A.; Gori, A.; Metrangolo, P. Chem. Commun. 2018, 54, 10718-10721. doi:10.1039/c8cc06010j

29. Pan, F.; Dashti, M.; Reynolds, M. R.; Rissanen, K.; Trant, J. F.; Beyeh, N. K. Beilstein J. Org. Chem. 2019, 15, 947-954. doi:10.3762/bjoc. 15.91 
30. Turunen, L.; Warzok, U.; Schalley, C. A.; Rissanen, K. Chem 2017, 3, 861-869. doi:10.1016/j.chempr.2017.08.010

31. Warzok, U.; Marianski, M.; Hoffmann, W.; Turunen, L.; Rissanen, K.; Pagel, K.; Schalley, C. A. Chem. Sci. 2018, 9, 8343-8351. doi:10.1039/c8sc03040e

32. Turunen, L.; Peuronen, A.; Forsblom, S.; Kalenius, E.; Lahtinen, M.; Rissanen, K. Chem. - Eur. J. 2017, 23, 11714-11718. doi:10.1002/chem.201702655

33. Turunen, L.; Warzok, U.; Puttreddy, R.; Beyeh, N. K.; Schalley, C. A.; Rissanen, K. Angew. Chem., Int. Ed. 2016, 55, 14033-14036. doi:10.1002/anie.201607789

34. Vanderkooy, A.; Gupta, A. K.; Földes, T.; Lindblad, S.; Orthaber, A.; Pápai, I.; Erdélyi, M. Angew. Chem., Int. Ed. 2019, 58, 9012-9016. doi:10.1002/anie.201904817

35. Nieland, E.; Topornicki, T.; Kunde, T.; Schmidt, B. M. Chem. Commun. 2019, 55, 8768-8771. doi:10.1039/c9cc03061a

36. Stranius, K.; Börjesson, K. Sci. Rep. 2017, 7, 41145 doi:10.1038/srep41145

37. Siampiringue, N.; Guyot, G.; Monti, S.; Bortolus, P. J. Photochem. 1987, 37, 185-188. doi:10.1016/0047-2670(87)85039-6

38. Bortolus, P.; Monti, S. J. Phys. Chem. 1979, 83, 648-652. doi:10.1021/j100469a002

39. Granucci, G.; Persico, M. Theor. Chem. Acc. 2007, 117, 1131-1143. doi:10.1007/s00214-006-0222-1

40. Weingart, O.; Lan, Z.; Koslowski, A.; Thiel, W. J. Phys. Chem. Lett. 2011, 2, 1506-1509. doi:10.1021/jz200474g

41. Gámez, J. A.; Weingart, O.; Koslowski, A.; Thiel, W. J. Chem. Theory Comput. 2012, 8, 2352-2358. doi:10.1021/ct300303s

42. Gámez, J. A.; Weingart, O.; Koslowski, A.; Thiel, W. Phys. Chem. Chem. Phys. 2013, 15, 11814-11821. doi:10.1039/c3cp51316e

43. Böckmann, M.; Doltsinis, N. L.; Marx, D. J. Phys. Chem. A 2010, 114, 745-754. doi:10.1021/jp910103b

44. Conti, I.; Garavelli, M.; Orlandi, G. J. Am. Chem. Soc. 2008, 130 , 5216-5230. doi:10.1021/ja710275e

45. Bléger, D.; Schwarz, J.; Brouwer, A. M.; Hecht, S. J. Am. Chem. Soc. 2012, 134, 20597-20600. doi:10.1021/ja310323y

46. Knie, C.; Utecht, M.; Zhao, F.; Kulla, H.; Kovalenko, S.; Brouwer, A. M.; Saalfrank, P.; Hecht, S.; Bléger, D. Chem. - Eur. J. 2014, 20 , 16492-16501. doi:10.1002/chem.201404649

47. Hübschle, C. B.; Dittrich, B. J. Appl. Crystallogr. 2011, 44, 238-240. doi:10.1107/s0021889810042482

48. Dumele, O.; Wu, D.; Trapp, N.; Goroff, N.; Diederich, F. Org. Lett. 2014, 16, 4722-4725. doi:10.1021/ol502099j

49. Canneaux, S.; Bohr, F.; Henon, E. J. Comput. Chem. 2014, 35, 82-93. doi:10.1002/jcc.23470

\section{License and Terms}

This is an Open Access article under the terms of the Creative Commons Attribution License (http://creativecommons.org/licenses/by/4.0). Please note that the reuse, redistribution and reproduction in particular requires that the authors and source are credited.

The license is subject to the Beilstein Journal of Organic Chemistry terms and conditions:

(https://www.beilstein-journals.org/bjoc)

The definitive version of this article is the electronic one which can be found at:

doi:10.3762/bjoc. 15.197 